\title{
Analysis of the Impact Factors on a Stable Warfarin Dose in Extreme Elderly (Age $\geq 80$ Years) Chinese Patients with Non-Valvular Atrial Fibrillation
}

\author{
Sen Wang, Jun Wu, Chen Men, Yan Guo* \\ Department of Geriatric Cardiology, First Affiliated Hospital of Nanjing Medical University, Nanjing, China \\ Email: *guoyan51@hotmail.com
}

How to cite this paper: Wang, S., Wu, J., Men, C. and Guo, Y. (2020) Analysis of the Impact Factors on a Stable Warfarin Dose in Extreme Elderly (Age $\geq 80$ Years) Chinese Patients with Non-Valvular Atrial Fibrillation. World Journal of Cardiovascular Diseases, 10, 329-336.

https://doi.org/10.4236/wjcd.2020.105031

Received: April 26, 2020

Accepted: May 25, 2020

Published: May 28, 2020

Copyright $\odot 2020$ by author(s) and Scientific Research Publishing Inc. This work is licensed under the Creative Commons Attribution International License (CC BY 4.0).

http://creativecommons.org/licenses/by/4.0/

\begin{abstract}
Purpose: The aim of this study was to investigate non-genetic and genetic factors contributing to stable warfarin dose change in the extreme elderly patients with non-valvular atrial fibrillation. Methods: A total of 40 elderly patients with stable warfarin doses were included in this study. Clinical basic data, such as age, sex, body mass index, basic disease like hypertension, diabetes and coronary heart disease had been recorded. Two nucleotide polymorphisms about VKORC1-1639G^A and CYP2C9 1075A^C genes were detected via sequencing by hybridization. Results: The elderly patients with CYP2C9 1075A^C (CA) genotype needed less warfarin daily doses than those with CYP2C9 $1075 \mathrm{~A}^{\wedge} \mathrm{C}(\mathrm{AA})$ genotype $(1.93 \pm 0.79 \mathrm{mg} / \mathrm{d}$ VS $2.15 \pm 0.64$ $\mathrm{mg} / \mathrm{d})$, but there was no significant difference $(\mathrm{p}=0.601)$. While the daily warfarin dose required for patients with VKORC1-1639G^A (AA) genotype was significantly lower than that for patients with VKORC1-1639G^A (GA) genotype $(2.00 \pm 0.67 \mathrm{mg} / \mathrm{d}$ VS $2.63 \pm 0.38 \mathrm{mg} / \mathrm{d}, \mathrm{p}=0.012)$. VKORC1-1639G^A together with age and diabetes status accounted $41.7 \%$ for dose variability. The new algorithm was developed using multivariate linear regression analysis; the model was developed for: Dose $=7.731-0.056^{\star}$ age $+0.527{ }^{\star} \mathrm{DM}-$ $0.785 *$ VKORC1. Conclusions: VKORC1-1639G^A together with age and diabetes status might predict warfarin doses in age $\geq 80$ years patients with non-valvular atrial fibrillation. In contrast, the polymorphism of CYP2C9 $1075 \mathrm{~A}^{\wedge} \mathrm{C}$ was not associated with dose variability.
\end{abstract}

\section{Keywords}

Extreme Elderly, Non-Valvular Atrial Fibrillation, VKORC1, CYP2C9 


\section{Introduction}

Non-valvular atrial fibrillation (NVAF) is a common arrhythmia and the disease incidence increases with age. Epidemiological studies have shown that the prevalence of NVAF among the elderly in China increases with age from a lower prevalence rate of $1.3 \%$ in the $60-69$ years age-group to approximately $7.5 \%$ for those who are 80 or 89 years [1]. In addition, stroke risk associated with atrial fibrillation also increases significantly with age, from only $1.5 \%$ in the $50-59$ years age-group to $23.5 \%$ in the 80 - 89 years age-group among patients with NVAF [2].

For more than 50 years, warfarin has been used to prevent stroke risk among patients with NVAF, although there are some limitations to its use [3] [4]. The major problems associated with warfarin are bleeding and thromboembolic events, both of which depend on the quality of anticoagulation, especially in older patients [5] [6]. It is difficult to achieve a stable anticoagulation control because different patients have a great variability of warfarin response [7]. This variability is mainly because of the vitamin K-epoxide reductase (VKORC1) polymorphisms and the cytochrome P450 enzyme gene (CYP2C9) polymorphisms, both of which affect warfarin metabolism [8] [9] [10]. Jia L et al. have found that in Chinese population, VKORC1 and CYP2C9 polymorphisms also play an important role in warfarin sensitivity [11]

To date, previous studies about the gene polymorphisms focused on the general patients or patients age $\geq 65$ years; there is little study focusing on the extreme elderly (age $\geq 80$ years) patients. Furthermore, elderly patients have more disease such as hypertension, coronary heart disease, and diabetes. The purpose of our study was to explore the effects of non-genetic and genetic factors on the stable warfarin doses variability in extreme elderly NVAF patients.

\section{Subjects and Methods}

\subsection{Study Population and Data}

We determined the study sample from all available patients who had NVAF from March 1, 2016 to March 1, 2018 in Jiangsu Province Hospital. This study was approved by the Ethics Committee of the First Affiliated Hospital of Nanjing Medical University. The inclusion criteria of study subjects included: 1) The patients were at least 80 years old; 2) CHADS2 score $\geq 2$ and they were eligible to take warfarin therapy; 3) They were received maintenance warfarin therapy, the INR ranged from 1.6 to 2.5 for at least 3 months. Exclusion criteria included: 1) Patients who were non-complicance with warfarin therapy and refused INR monitoring; 2) Patients who had abnormal liver function (AST, ALT $\geq 3$ fold the upper limit of normal); 3) Patients who were taking amiodarone or antiplatelet drug such as aspirin or clopidogrel. At last, 40 patients with warfarin anticoagulant therapy were included in the study and every patient signed the written informed consent. 


\subsection{Study and Genotyping Protocol}

Two tubes of blood were taken 12 to $16 \mathrm{~h}$ after the last dose of warfarin taking. One Citrate anticoagulant tube of blood sample $(3 \mathrm{ml})$ was collected to record latest INR. Another EDTA anticoagulant tube of blood sample $(3 \mathrm{~mL})$ was collected to detect gene polymorphism. After the plasma was removed by centrifugation, blood cells were stored at $-80^{\circ} \mathrm{C}$ for DNA extraction (Yaojinbao Kit, China). Add 1.5 ul treated blood cells to the gene sequencing kit (Yaojinfen Kit, China), close the tube tightly, mix them well and centrifugate them for a short time. PCR reactions were performed by a fluorescence detector (TianLong, Xian, China).

\subsection{Statistical Analysis}

Continuous data was expressed as mean \pm standard deviation. Statistical analysis was performed using SPSS 22.0 (SPSS Inc., Chicago, IL, USA).

\section{Results}

The clinical characteristics of 40 patients ( 27 men and 13 women) were shown in Table 1. The age of these patients varied from 80.0 - 97.0 years and the average age was $87.68 \pm 4.91$ years. BMI values range from 16.3 to $31.9 \mathrm{~kg} / \mathrm{m}^{2}$ and the average BMI was $23.1 \mathrm{~kg} / \mathrm{m}^{2}$. The average daily doses of warfarin were $2.11 \pm$ $0.67 \mathrm{mg}$. The average INR of all patients was $1.99 \pm 0.37$. Among 40 patients, 28 patients $(70.0 \%)$ have hypertention, 21 patients (52.5\%) have CHD and 11 patients $(27.5 \%)$ have diabetes.

Table 1. Patient characteristics.

\begin{tabular}{cc}
\hline Parameters & Data \\
Sex $(\mathrm{M} / \mathrm{F})$ & $27 / 13$ \\
Age & $87.68 \pm 4.91$ \\
BMI $\left(\mathrm{Kg} / \mathrm{m}^{2}\right)$ & $23.07 \pm 3.58$ \\
Warfarin daily doses $(\mathrm{mg})$ & $2.11 \pm 0.67$ \\
Average INR & $1.99 \pm 0.37$ \\
ALT (U/L) & $18.96 \pm 8.15$ \\
AST (U/L) & $24.34 \pm 8.31$ \\
Cr ( $\mu$ mol/L) & $91.80 \pm 29.27$ \\
Urea (mmol/L) & $7.22 \pm 2.82$ \\
HbAlc (\%) & $6.37 \pm 1.07$ \\
hypertension & $28(70 \%)$ \\
CHD & $21(52.5 \%)$ \\
DMistory & $11(27.5 \%)$ \\
\hline
\end{tabular}

Note: Data are presented as either mean \pm SD or counts. Abbreviations: M/F, male/female; BMI, body mass index; ALT, Alanine aminotransferase; AST, aspartate aminotransferase; $\mathrm{Cr}$, creatinine; Urea, urea nitrogen; HbAlc, glycosylated hemoglobin; CHD, coronary heart disease; DM, diabetes. 
Table 2 summarized the genotype frequencies of VKORC1 and CYP2C9 genes polymorphisms and the comparisons of warfarin doses in these patients. The daily warfarin dose required for patients with the AA genotype of VKORC1-1639G^A was significantly lower than that for the patients with GA genotype $(\mathrm{p}<0.05)$, while the dosage required for patients with variant genotypes of CYP2C9-1075A $>C$ showed no difference.

Multivariate linear regression analysis was carried out with the stable daily doses of warfarin as the dependent variable; the age, sex, history of hypertension, diabetes or CHD and genotypes of CYP2C9 or VKORC1 as the independent variable. The results showed that age, diabetes history and VKORC1 genotype were independent factors influencing the stable daily dose of warfarin (Table 3). To derive a patient's daily warfarin dose, a clinician would use the patients's specific clinical and genomic characteristics to complete the following equation: Dose $=7.731-0.056^{\star}$ age $+0.527{ }^{\star} \mathrm{DM}-0.785^{\star}$ VKORC1 $(\mathrm{DM}$ : defined as the history of diabetes, input 1 if the patient has the history of diabetes; VKORC1: the presence of VKORC1-1639G^A (AA) is denoted by a " 1 " and the presence of VKORC1-1639G^A (GA) is denoted by a “0”). The stepwise multivariate linear regression model for warfarin doses revealed that diabetes history, VKORC1

Table 2. Differences in stable daily doses of warfarin among genotypes.

\begin{tabular}{cccc}
\hline Genotype & $\begin{array}{c}\text { Numbers of } \\
\text { patients }(\%)\end{array}$ & $\begin{array}{c}\text { Stable daily doses } \\
(\text { Mean } \pm \text { SD })\end{array}$ & p value \\
VKORC1-1639G $>$ A & p $=\mathbf{0 . 0 1 2}$ \\
GA & $33(82.5)$ & $2.00 \pm 0.67$ & \\
AA & $7(17.5)$ & $2.63 \pm 0.38$ & \\
CA & $33(82.5)$ & $2.15 \pm 0.64$ & $\mathrm{p}=0.601$ \\
\hline
\end{tabular}

Abbreviations: VKORC1, vitamin K-epoxide reductase; CYP2C9, cytochrome P450 enzyme gene.

Table 3. Multivariate regression model for predicting warfarin dose.

\begin{tabular}{ccccc}
\hline Predictor & Coefficient & SE & T & P \\
\hline Intercept & 7.731 & 1.709 & 4.525 & $\mathbf{0 . 0 0 0}$ \\
Age & -0.056 & 0.019 & -2.971 & $\mathbf{0 . 0 0 6}$ \\
Sex & -0.195 & 0.219 & -0.892 & 0.379 \\
Hypertension & -0.220 & 0.213 & -1.030 & 0.311 \\
Diabetes & 0.527 & 0.222 & 2.371 & $\mathbf{0 . 0 2 4}$ \\
CHD & 0.162 & 0.210 & 0.774 & 0.444 \\
CYP2C9 & -0.361 & 0.257 & -1.405 & 0.170 \\
VKORC1 & -0.785 & 0.241 & -3.258 & $\mathbf{0 . 0 0 3}$ \\
\hline
\end{tabular}

Abbreviations: CHD, coronary heart disease; VKORC1, vitamin K-epoxide reductase; CYP2C9, cytochrome P450 enzyme gene. 
polymorphisms and age could explain $15.0 \%, 17.5 \%$ and $9.2 \%$ of interindividual variance, respectively. Overall, the algorithm could account for $41.7 \%$ of the warfarin dose variability (Table 4).

\section{Discussion}

The main findings of this study were as follows: 1) The genetic factors VKORC1-1639G^A, together with non-genetic factors of age and diabetes history might predict warfarin doses in extremely elderly patients with NVAF. 2) The polymorphism of CYP2C9-1075A $>\mathrm{C}$ did not contribute to daily warfarin dose variability in these patients. This is the first attempt to extract the most commonly used genetic and non-genetic factors influencing warfarin sensitivity in extreme elderly (age $\geq 80$ years) Chinese Patients with NVAF.

Elderly patients with NVAF both have much higher risk of stroke because of co-morbidities such as hypertension, diabetes and chronic kidney disease [12] and a higher risk of major bleeding because of decreased organ function, polypharmacy and other bleeding risk factors [12] [13]. At the same time, warfarin therapeutic index is narrow and individual dosage of patients varies greatly. Therefore, it is very important to identify the individual differences response to warfarin in elderly people.

Previous studies have shown that genetic variants in CYP2C9 and VKORC1 can explain approximately one third of the interpatient warfarin dose variance and are more strongly associated with a stable warfarin dose than all other known patient factors [10] [14] [15]. Results from our study revealed that the patient with the genotype of VKORC1-1639G^A (AA) needed lower daily warfarin doses than VKORC1-1639G^A (GA), while CYP2C9 1075A^C did not contribute to dose variability in extremely elderly patients. The difference between our study and previous studies may be due to the race and age. Compared with other racial groups, the prevalence of CYP2C9 1075A^C is lower in Asians and the variation of $\mathrm{CYP} 2 \mathrm{C} 91075 \mathrm{~A}^{\wedge} \mathrm{C}$ has less effect on warfarin TTR [16]. Meanwhile, the contribution of VKORC1-1639G^A was much larger than that of $\mathrm{CYP} 2 \mathrm{C} 91075 \mathrm{~A}^{\wedge} \mathrm{C}$, which was consistent with previous research results [17] [18]. In the multivariate regression analysis, only age, diabetes history and VKORC1-1639G^A was retained in our final algorithm. Increasing age, variant genotypes of VKORC1-1639G^A (AA) were negatively associated with warfarin dose while diabetes history showed positive correlations. The results of age and VKORC1-1639G^A is consistent with almost all previous studies. There are

Table 4. Final model produced by stepwise regression analysis.

\begin{tabular}{cccc}
\hline Predictor & Cumulative Model R2 (\%) & Contribution (\%) & $\mathbf{P}$ \\
\hline Diabetes & 15.0 & 15.0 & $\mathbf{0 . 0 0 1}$ \\
VKORC1 & 32.5 & 17.5 & $\mathbf{0 . 0 0 2}$ \\
Age & 41.7 & 9.2 & $\mathbf{0 . 0 2 2}$ \\
\hline
\end{tabular}

Abbreviations: VKORC1, vitamin K-epoxide reductase. 
also some studies about the diabetes status and warfarin maintenance doses. But the results were inconsistent. The Hillman groups [19] found that no univariate correlation between diabetes and warfarin maintenance dose. While Lenzini groups [20] found a negative correlation between diabetes and warfarin dose, while the Garcia group [21] and Jinxing Chen group [17] observed a positive correlation between diabetes and warfarin dose. Our result showed that in extreme elderly Chinese Patients, patients with diabetes got a relatively higher dose of warfarin $(2.52 \pm 0.69 \mathrm{mg} /$ day vs. $1.95 \pm 0.59 \mathrm{mg} /$ day, $\mathrm{P}=0.014)$. In the final regression model, diabetes also showed a significant association $(P=0.024)$. In many previous studies, smoking status, amiodarone and antiplated drug use were included in the final regression models. However, as our patients were extremely elderly patients, there were no smoking people and patients used amiodarone, and antiplatelet drug was excluded before recruit.

Several limitations exist in our study. First, these are results from a single center in China. Therefore we can't extend our findings to other racial groups. Second, there were only 40 patients in our study, relatively small number were examined and owing to the small number and we didn't study vascular events. Lastly, this is a retrospective study. Further prospective and multi-center studies are needed to confirm our findings and the ischemic and hemorrhagic events need to be studied in the further study.

\section{Conclusion}

In summary, results in our study show that the genetic factors VKORC1 $\left(-1639 \mathrm{G}^{\wedge} \mathrm{A}\right)$ and non-genetic factors such as age and diabetes history are important in determining the warfarin stable daily doses in Chinese extreme elderly NVAF patients. It may be potentially useful in guiding prescribers to make decision on warfarin dosing in age $\geq 80$ years patients.

\section{Acknowledgments}

This study is supported by the National Scientific Foundation of China (NSFC No. 81100123). We gratefully thank the help of Miao Guo and the Research Institute of pharmacy of the First Affiliated Hospital of Nanjing Medical University.

\section{Conflicts of Interest}

The authors declare no conflicts of interest regarding the publication of this paper.

\section{References}

[1] Zhou, Z. and Hu, D. (2008) An Epidemiological Study on the Prevalence of Atrial Fibrillation in the Chinese Population of Mainland China. The Journal of Epidemiology, 18, 209-216. https://doi.org/10.2188/jea.JE2008021

[2] Lin, H.J., Wolf, P.A., Kelly-Hayes, M., Beiser, A.S., Kase, C.S., Benjamin, E.J. and 
D’Agostino, R.B. (1996) Stroke Severity in Atrial Fibrillation. The Framingham Study. Stroke, 27, 1760-1764. https://doi.org/10.1161/01.STR.27.10.1760

[3] Pitt, A., Ruff, C.T. and Giugliano, R.P. (2016) Non-Vitamin K Antagonist Oral Anticoagulants in Atrial Fibrillation. Hematology/Oncology Clinics of North America, 30, 1019-1034. https://doi.org/10.1016/j.hoc.2016.05.002

[4] Go, A.S., Hylek, E.M., Borowsky, L.H., Phillips, K.A., Selby, J.V. and Singer, D.E. (1999) Warfarin Use among Ambulatory Patients with Nonvalvular Atrial Fibrillation: The Anticoagulation and Risk Factors in Atrial Fibrillation (ATRIA) Study. Annals of Internal Medicine, 131, 927-934. https://doi.org/10.7326/0003-4819-131-12-199912210-00004

[5] Connolly, S.J., Pogue, J., Eikelboom, J., Flaker, G., Commerford, P., Franzosi, M.G., Healey, J.S., Yusuf, S. and Investigators, A.W. (2008) Benefit of Oral Anticoagulant over Antiplatelet Therapy in Atrial Fibrillation Depends on the Quality of International Normalized Ratio Control Achieved by Centers and Countries as Measured by Time in Therapeutic Range. Circulation, 118, 2029-2037. https://doi.org/10.1161/CIRCULATIONAHA.107.750000

[6] Gallagher, A.M., de Vries, F., Plumb, J.M., Hass, B., Clemens, A. and van Staa, T.P. (2012) Quality of INR Control and Outcomes Following Venous Thromboembolism. Clinical and Applied Thrombosis/ Hemostasis, 18, 370-378. https://doi.org/10.1177/1076029611426139

[7] Voora, D., McLeod, H.L., Eby, C. and Gage, B.F. (2005) The Pharmacogenetics of Coumarin Therapy. Pharmacogenomics, 6, 503-513. https://doi.org/10.2217/14622416.6.5.503

[8] Sconce, E.A., Khan, T.I., Wynne, H.A., Avery, P., Monkhouse, L., King, B.P., Wood, P., Kesteven, P., Daly, A.K. and Kamali, F. (2005) The Impact of CYP2C9 and VKORC1 Genetic Polymorphism and Patient Characteristics upon Warfarin Dose Requirements: Proposal for a New Dosing Regimen. Blood, 106, 2329-2333. https://doi.org/10.1182/blood-2005-03-1108

[9] Carlquist, J.F., Horne, B.D., Muhlestein, J.B., Lappe, D.L., Whiting, B.M., Kolek, M.J., Clarke, J.L., James, B.C. and Anderson, J.L. (2006) Genotypes of the Cytochrome p450 Isoform, CYP2C9, and the Vitamin K Epoxide Reductase Complex Subunit 1 Conjointly Determine Stable Warfarin Dose: A Prospective Study. Journal of Thrombosis and Thrombolysis, 22, 191-197.

https://doi.org/10.1007/s11239-006-9030-7

[10] Rieder, M.J., Reiner, A.P., Gage, B.F., Nickerson, D.A., Eby, C.S., McLeod, H.L., Blough, D.K., Thummel, K.E., Veenstra, D.L. and Rettie, A.E. (2005) Effect of VKORC1 Haplotypes on Transcriptional Regulation and Warfarin Dose. The New England Journal of Medicine, 352, 2285-2293. https://doi.org/10.1056/NEJMoa044503

[11] Jia, L., Wang, Z., Men, J., Cai, H. and Wei, M. (2017) Polymorphisms of VKORC1 and CYP2C9 Are Associated with Warfarin Sensitivity in Chinese Population. Therapeutics and Clinical Risk Management, 13, 421-425. https://doi.org/10.2147/TCRM.S130198

[12] Kirchhof, P., Benussi, S., Kotecha, D., Ahlsson, A., Atar, D., Casadei, B., Castella, M., Diener, H.C., Heidbuchel, H., Hendriks, J., Hindricks, G., Manolis, A.S., Oldgren, J., Popescu, B.A., Schotten, U., Putte, B.V., Vardas, P. and ESC Scientific Document Group (2016) ESC Guidelines for the Management of Atrial Fibrillation Developed in Collaboration with EACTS. European Heart Journal, 37, 2893-2962. https://doi.org/10.1093/eurheartj/ehw210 
[13] Bando, S., Nishikado, A., Hiura, N., Ikeda, S., Kakutani, A., Yamamoto, K., Kaname, N., Fukatani, M., Takagi, Y., Yukiiri, K., Fukuda, Y. and Nakaya, Y. (2018) Efficacy and Safety of Rivaroxaban in Extreme Elderly Patients with Atrial Fibrillation: Analysis of the Shikoku Rivaroxaban Registry Trial (SRRT). Journal of Cardiology, 71, 197-201. https://doi.org/10.1016/j.jjcc.2017.08.005

[14] D’Andrea, G., D’Ambrosio, R.L., Perna, P.D., Chetta, M., Santacroce, R., Brancaccio, V., Grandone, E. and Margaglione, M. (2005) A Polymorphism in the VKORC1 Gene Is Associated with an Interindividual Variability in the Dose-Anticoagulant Effect of Warfarin. Blood, 105, 645-649. https://doi.org/10.1182/blood-2004-06-2111

[15] Jofe, H.V., Xu, R.L., Johnson, F.B., Longtine, J., Kucher, N. and Goldhaber, S.Z. (2004) Warfarin Dosing and Cytochrome P450 2C9 Polymorphisms. Thrombosis and Haemostasis, 91, 1123-1128. https://doi.org/10.1160/TH04-02-0083

[16] Park, Y.K., Lee, M.J., Kim, J.H., Lee, J.S., Park, R.W., Kim, G.M., Chung, C.S., Lee, K.H., Kim, J.S., Lee, S.Y. and Bang, O.Y. (2017) Genetic and Non-Genetic Factors Affecting the Quality of Anticoagulation Control and Vascular Events in Atrial Fibrillation. Journal of Stroke and Cerebrovascular Diseases, 26, 1383-1390. https://doi.org/10.1016/j.jstrokecerebrovasdis.2017.02.022

[17] Chen, J., Shao, L., Gong, L., Luo, F., Wang, J., Shi, Y., Tan, Y., Chen, Q., Zhang, Y., Hui, R. and Wang, Y. (2014) A Pharmacogenetics-Based Warfarin Maintenance Dosing Algorithm from Northern Chinese Patients. PLoS ONE, 9, e105250. https://doi.org/10.1371/journal.pone.0105250

[18] Li, B., Liu, R., Wang, C., Ren, C., Zhang, S., Zhang, F., Zhang, J., Liu, S., Wei, Y., Liu, W., Song, B. and Wu, X. (2019) Impact of Genetic and Clinical Factors on Warfarin Therapy in Patients Early after Heart Valve Replacement Surgery. European Journal of Clinical Pharmacology, 75, 1685-1693. https://doi.org/10.1007/s00228-019-02747-5

[19] Hillman, M.A., Wilke, R.A., Caldwell, M.D., Berg, R.L., Glurich, I. and Burmester, J.K. (2004) Relative Impact of Covariates in Prescribing Warfarin According to CYP2C9 Genotype. Pharmacogenetics, 14, 539-547. https://doi.org/10.1097/01.fpc.0000114760.08559.dc

[20] Lenzini, P., Wadelius, M., Kimmel, S., Anderson, J.L., Jorgensen, A.L., Pirmohamed, M., Caldwell, M.D., Limdi, N., Burmester, J.K., Dowd, M.B., Angchaisuksiri, P., Bass, A.R., Chen, J., Eriksson, N., Rane, A., Lindh, J.D., Carlquist, J.F., Horne, B.D., Grice, G., Milligan, P.E., Eby, C., Shin, J., Kim, H., Kurnik, D., Stein, C.M., McMillin, G., Pendleton, R.C., Berg, R.L., Deloukas, P. and Gage, B.F. (2010) Integration of Genetic, Clinical, and INR Data to Refine Warfarin Dosing. Clinical Pharmacology \& Therapeutics, 87, 572-578. https://doi.org/10.1038/clpt.2010.13

[21] Garcia, D., Regan, S., Crowther, M., Hughes, R.A. and Hylek, E.M. (2005) Warfarin Maintenance Dosing Patterns in Clinical Practice: Implications for Safer Anticoagulation in the Elderly Population. Chest, 127, 2049-2056.

https://doi.org/10.1378/chest.127.6.2049 